\title{
Nação, narração e naturalismo em Bom-Crioulo, de Adolfo Caminha
}

\author{
Patrícia I. Martinho Ferreira ${ }^{1}$ \\ Brown University, USA
}

\begin{abstract}
Resumo: Partindo da ideia de sistema literário formulada por Antonio Candido, propõe-se neste ensaio estabelecer um diálogo entre Iracema (1865), de José de Alencar e Bom-Crioulo (1895) de Adolfo Caminha, com um duplo objetivo. Primeiro, entender de que forma BomCrioulo retoma e expande as fragilidades do sistema político-social estabelecido pelas elites do Império e presentes já nas entrelinhas da narrativa alencariana. Segundo, perceber de que forma Bom-Crioulo pode contribuir para a construção da identidade brasileira e, por conseguinte, participar na interação que se estabelece entre nação e narração. $O$ foco principal deste ensaio será o romance de Caminha, embora o ponto de partida seja o jogo intertextual que este mantém com Iracema.
\end{abstract}

Palavras-chave: Nação. Narração. Identidade brasileira. Bom-Crioulo. Intertextualidade.

$\mathrm{Na}$ "Introdução" à Formação da Literatura Brasileira, Antonio Candido advoga a existência de uma tradição literária brasileira, observando a presença, no Brasil, desde meados do século XVIII, de uma "continuidade ininterrupta de obras e autores, cientes quase sempre de integrarem um processo de formação literária" (CANDIDO, 1975, p. 24). Autores que, conscientemente, partilham certos denominadores comuns como, por exemplo, a linguagem, os temas e os traços de natureza psíquico-social, sendo que essa partilha se concretiza através da aceitação ou da rejeição desses pontos de contato. Luiz Fernando Valente, num artigo dedicado à tradição alencariana, aproxima-se justamente desta visão pertinente ao "sistema literário" formulada por Candido demonstrando que José de Alencar (1829-1877) pode funcionar na literatura brasileira (aquela que se centra particularmente sobre a questão da fundação e da identidade da nação) como uma "figura catalisadora (...) cuja obra representa, ao mesmo tempo, uma maturação das preocupações do passado, e uma consciência nascente das dificuldades do presente, que abre o caminho para desenvolvimentos futuros" (VALENTE, 1994, p. 142).

Partindo, deste modo, da ideia de continuidade no sistema literário e acreditando que Adolfo Caminha (1867-1897) terá certamente lido Alencar, proponho estabelecer um diálogo

\footnotetext{
${ }^{1}$ Patrícia I. Martinho Ferreira é Licenciada em Estudos Portugueses (2005), Mestre em Teoria e Análise da Narrativa (2009) pela Faculdade de Letras da Universidade de Coimbra (Portugal) e Mestre em Ensino de Português como Língua Estrangeira (2012) pela Faculdade de Letras da Universidade do Porto (Portugal). Atualmente frequenta o Doutorado em Estudos Portugueses e Brasileiros na Universidade de Brown (EUA). Tem apresentado trabalhos nas áreas de literatura portuguesa, brasileira e africanas de expressão portuguesa. 
entre Bom-Crioulo (1895) e Iracema (1865), na tentativa de compreender a forma pela qual Bom-Crioulo retoma e expande as fragilidades do sistema político-social estabelecido pelas elites do Império, iminentes nas entrelinhas da narrativa alencariana. Analisaremos também de que maneira Bom-Crioulo pode contribuir para a construção da identidade brasileira enfatizando, por conseguinte, a interação entre nação e narração. $O$ foco principal deste ensaio será o romance de Caminha, embora o ponto de partida seja o jogo intertextual que este mantém com o romance de Alencar.

No artigo “Alencar's Flawed Blueprints", Luiz Fernando Valente explica que, para se entender o projeto literário de Alencar, é necessário considerar as ambiguidades que o caracterizam, cujo embate é decorrente, em termos gerais, de uma perspectiva elitista, reproduzida pelo escritor, e a realidade histórica que observou e vivenciou. Isso significa irmos além das leituras canônicas que veem na sua obra e, no caso que aqui nos interessa, em Iracema, uma celebração não problemática das implicações políticas associadas à fundação do Brasil. De fato, o que se sublinha nesse artigo é a ideia de que Alencar estava consciente da complexidade do seu tempo histórico e do projeto de pensar uma nação conciliando forças contraditórias. Por isso, em Iracema, a descrição da violência e da destruição associadas à presença do colonizador português é minimizada através da preservação da ordem e da imagem celebratória da natureza do Brasil, cujo símbolo máximo é a beleza exótica da mulher indígena. Assim sendo, é redutor ver em Iracema apenas a glorificação da natureza brasileira, sem compreender a noção de perda que lhe está associada. Valente sintetiza esta questão da seguinte forma:

Iracema, que ostensivamente começa como uma celebração das origens do Brasil na mistura harmônica de raças e culturas, acaba por narrar a violação da terra brasileira e a destruição da cultura indígena pelo colonizador português, cujos valores se revelam dominantes: tendo cumprido seu papel ao dar a luz a Moacir, Iracema morre, exilada de sua tribo e de sua terra natal, enquanto Poti se cristianiza, tornando-se eventualmente herói da causa portuguesa contra os holandeses (VALENTE, 1994, p. 144).

São justamente as ambiguidades e as ambivalências da obra de Alencar que serão recuperadas, incorporadas, rejeitadas e, até de certa forma, resolvidas por alguns autores que lhe sucedem. A aproximação de Iracema e Bom-Crioulo, neste contexto, poderá ser inusitada na medida em que, à primeira vista, muito pouco têm em comum. Com efeito, ao contrário de Alencar, Caminha não está preocupado com o projeto da fundação mítica da nação brasileira. Ao escrever sob o signo do Naturalismo e já não do Romantismo, este autor propõe lançar um olhar sobre a sociedade urbana brasileira, dialogando e expondo alguns dos seus 
problemas, tais como a miséria das classes populares, a violência do trabalho braçal dentro da Marinha, o racismo e a homossexualidade.

Seja como for, mesmo que em termos temáticos, formais, propósitos e valor literário, estes dois livros se afastem, não há como deixar de estabelecer alguns pontos de contato. Acredito, por exemplo, que a imagem com que Caminha inicia Bom-Crioulo remete à abertura de Iracema, mesmo que isso aconteça de forma invertida. O diálogo intertextual parece estabelecer-se, no plano da linguagem, através da mesma cadência do discurso que provem do uso de frases curtas e, no plano imagético, através da imagem da imensidão do mar, onde desliza, em Iracema, um "barco aventureiro" e, em Bom-Crioulo, a sua "sombra fantástica”. O elemento de aproximação que se intui da leitura destas duas passagens inaugurais encontra-se na ideia de movimento a partir da qual a imagem é construída, embora essa ideia, no romance de Caminha, surja profundamente marcada por sentimentos negativos. Se em Iracema o "barco aventureiro" resvala e sulca as ondas desaparecendo rapidamente no mar em direção à pátria do homem branco, em Bom-Crioulo, "a sombra fantástica d[o] barco aventureiro" já não se assemelha à "galera de lenda, branca e leve no mar alto, grimpando serena o corcovo das ondas!", visto que agora é um esquife agourento que singra as águas da pátria numa marcha lenta, "como se fora um grande morcego apocalíptico de asas abertas sobre o mar" (CAMINHA, 1991, p. 23).

O tom de monotonia e pessimismo com que o narrador de Bom Crioulo descreve a triste e desolada paisagem contraria o elogio à natureza brasileira realizado na abertura de Iracema. Porém, o que é curioso é que de ambos os textos ressalta uma noção de perda. No que diz respeito ao início de Iracema, essa ideia de perda vislumbra-se no olhar do "moço guerreiro" que fica "preso na sombra fugitiva da terra", assim como no seu "agro sorriso" que a morte de Iracema certamente lhe provoca (ALENCAR, 1948, p. 45). No caso de BomCrioulo, a ideia de falta materializa-se na deterioração da "velha e gloriosa corveta", isto é, numa atmosfera de estagnação e decadência que aponta para um tempo glorioso no passado e, simultaneamente, para a claustrofobia política e social que caracteriza o presente histórico da publicação do romance, ou seja, os primeiros anos do regime republicano. Ainda que apontando para ideias diferentes, a noção de perda e de distopia é uma peça fundamental para a construção narrativa dos dois textos.

Se assumirmos que a abertura de Bom-Crioulo é uma simples paródia do texto de Alencar, talvez se possa também dizer que Caminha leu Iracema sem ter percebido bem as ambiguidades acima referidas, isto é, sem ter percebido que a par do tom laudatório e utópico, existe em Iracema igualmente certa noção de distopia, assente, sobretudo, na SOLETRAS - Revista do Departamento de Letras da FFP/UERJ 
questão da violência exercida pelo colonizador sobre a paisagem natural e humana da terra brasileira. Aliás, é importante referir que o tom elegíaco da abertura de Iracema é, desde logo, um sintoma dessa visão crítica que Alencar inevitavelmente acabou por inscrever no seu texto.

No caso de Caminha se ter apercebido das ambivalências da proposta de Alencar, o que se evidencia é o diálogo intertextual e, assim sendo, pode afirmar-se que Caminha retoma de forma muito consciente a ideia de perda que se intui no texto de Iracema. É essa justamente a nossa hipótese interpretativa: a noção de perda - que se vai construindo ao longo da leitura de Iracema e que culmina no final do livro com a ausência do canto da Jandaia - é retomada, sob um outro viés, em Bom-Crioulo. No caso deste romance, o viés é o da violência, já não o da violência do colonizador sobre o indígena como em Iracema, mas, sim, o da violência do homem branco sobre o negro dentro da sociedade brasileira pósabolição da escravatura. Dito de outro modo, o livro aborda, portanto, a violência das classes abastadas sobre as classes menos favorecidas. Ao colocarmos o enfoque na questão da violência física sobre o subalterno, a homossexualidade não resume a problemática deste romance, mas é encarada apenas como mais um traço que caracteriza o protagonista, tal como a cor da sua pele e a sua classe social. A aproximação que vemos entre os dois incipit é, portanto, uma inversão com distância crítica e não propriamente uma paródia do texto de Alencar, já que para isso teríamos de ter uma repetição dos termos, de acordo com a interpretação que Linda Hutcheon confere a este conceito (HUTCHEON, 1989, p. 17).

Outro momento em que é possível entrever um jogo intertextual com Iracema surge quando o narrador de Caminha, ao apresentar a figura de um marinheiro negro, destaca os seus olhos muito brancos, os seus lábios enormemente grossos, o seu vago sorriso idiota e a sua fisionomia marcada pela estupidez e pela subserviência (CAMINHA, 1991, p. 24). O diálogo com o texto de Alencar está precisamente na inversão dos termos e das imagens que o autor emprega para apresentar o elemento indígena. Ao contrário do exótico marinheiro negro, nada na figura de Iracema é grosseiro, desarmonioso ou subserviente; pelo contrário, o seu sorriso é doce, os seus lábios são de mel e os seus pés levam a indígena a correr pelo sertão com gracilidade e em total consonância com a exuberância da paisagem natural em que se insere.

Ao aproximarmos os dois romances, há, para além das intertextualidades já apontadas, duas passagens que parecem invocar a obra de Alencar no que nela existe de elogio à natureza brasileira. A primeira diz respeito ao episódio em que Amaro descreve com um entusiasmado patriotismo a paisagem da costa fluminense a Aleixo, no instante em que a 
corveta aporta no Rio de Janeiro: "E começou a descrever o pedaço do litoral que se ia desdobrando à luz, alcantilado e fulgurante, como essas terras lendárias de tamoios e caramurus... (...) E foi indicando, um a um, com exclamações de patriotismo, os acidentes da entrada, os edifícios" (CAMINHA, 1991, p. 40); a segunda encontra-se no momento em que o narrador nos oferece um breve apontamento sobre a paisagem natural que se observa da janela da enfermaria em que Amado se encontra: "grande sala que dizia para o mar e donde se gozava um belíssimo aspeto de natureza americana" (CAMINHA, 1991, p. 86). Estes dois exemplos permitem afirmar que a narrativa de Bom-Crioulo, embora se centre na paisagem urbana, não deixa de incluir certos comentários que destacam de forma muito positiva a exuberância da natureza brasileira e, nesse sentido, o diálogo de Caminha com a escrita de Alencar ganha mais pertinência.

Publicado 30 anos depois de Iracema, Bom-Crioulo é, se não o primeiro, um dos primeiros romances brasileiros a ter um negro (e não um mulato ou um caboclo) como personagem principal e talvez seja o primeiro a tratar de forma não moralizadora o tema da homossexualidade. Bom-Crioulo foi escrito numa época marcada pela inflação crônica, pela instabilidade social e por um nacionalismo exaltado. Em setembro de 1893, por exemplo, a Marinha rebela-se contra o governo militar chefiado por Floriano Peixoto e bombardeia a cidade do Rio de Janeiro, agitando as águas da recente República. Além disso, a questão de fundo na sociedade brasileira continuava a ser a dificuldade de assegurar o desenvolvimento econômico e a força de trabalho necessária para atingi-lo, questão na qual a mão de obra do negro e do imigrante europeu será crucial. A violência que percorre toda a narrativa, e que está presente especificamente através do castigo da chibata a que eram submetidos os marinheiros (sobretudo negros e mulatos), é apenas um exemplo dessa agitação políticosocial vivida no fim do século XIX. Acresce, ainda, que a incorporação do elemento negro nesta narrativa pode ser vista como uma tentativa de responder às narrativas românticas que tinham, no sentido de Ernest Renan, esquecido este elemento racial no seu discurso da construção da nação. ${ }^{2}$ Colocando o elemento negro no espaço literário, isto é, no espaço em

\footnotetext{
${ }^{2}$ Parece-me fundamental lembrar, neste contexto, a argumentação de Ernest Renan apresentada no artigo "What is a nation?" (in Nation and Narration, 1990). Para este filósofo e historiador francês, a História é encarada como um processo e, por conseguinte, a construção da nação faz parte desse processo dinâmico e fluido, no qual estão em causa laços de solidariedade e interesses entre membros de uma mesma comunidade. Nesse processo, a questão do esquecimento é um ponto central, já que, para além dos laços em comum, os membros dessa comunidade precisam de esquecer muitas coisas para encontrarem uma certa estabilidade. Segundo o autor, é difícil construir uma unidade sem alguma brutalidade ou exclusão. No caso da construção da nação brasileira, o elemento negro é precisamente o exemplo máximo desse ato de exclusão, já que nas narrativas românticas de fundação mítica ele não tem qualquer lugar. 
que, por excelência, a nação é construída e narrada, o autor de Bom-Crioulo abre caminho para uma reflexão mais inclusiva sobre a identidade brasileira.

No estudo Tal Brasil, Qual Romance?, Flora Sussekind insere Bom-Crioulo na tradição do romance naturalista brasileiro, reconhecendo que, por um lado, Caminha foi inovador ao ser capaz de romper com essa mesma tradição, escolhendo, com uma linguagem seca, tratar acerca das relações de trabalho e hierarquias sociais, através do percurso de vida de um protagonista negro, homossexual e pertencente às camadas populares; contudo, por outro lado, foi incapaz de se afastar do "horizonte pseudocientífico dos estudos raciais europeus" (SUSSEKIND, 1984, p. 138), condenando duplamente a raça negra, através do trabalho assente na força física e de um determinismo patológico que conduziria necessariamente ao crime. De acordo com a autora, Caminha oferece, neste livro, um corte contraditório com a tradição naturalista, visto que "corta, quando escolhe um protagonista negro, pobre e homossexual, quando privilegia relações de trabalho e paixões desviantes ao invés dos laços de família", porém, reinstala as premissas do Naturalismo "quando em seu texto reforça uma ciência racista. Quando não se deixa o negro falar, e sim que teorias de inferioridade racial falem por ele" (SUSSEKIND, 1984, p. 139).

A leitura que fazemos deste romance afasta-se desta proposta radical de Flora Sussekind, uma vez que preferimos ver as contradições de Caminha como sinal de ambiguidade, e não como sinal de uma atitude de "fé cega" na ciência da época. Com efeito, apesar de o romance ter aparecido num contexto histórico em que a constituição da homossexualidade era difundida nos discursos jurídicos e médicos como doença e crime, e apesar de o vocabulário usado pelo narrador ao longo do romance ser pejorativo quando relacionado com a homossexualidade, não me parece haver uma afirmação unívoca desse discurso na narrativa de Caminha. Deste modo, prefiro ler o tom moralista que por vezes emerge em Bom-Crioulo não como uma hipotética visão racista do autor, mas, sim, como um diálogo direto com a forma com que as práticas desviantes e, por extensão, a homossexualidade, eram encaradas no meio social retratado. Nesse sentido, a proposta literária de Caminha não é apenas uma visão documental da sociedade, mas um diálogo e uma interação com essa sociedade, a sociedade do final do Império e início da República. Assim, se pode dizer que existe neste romance um confronto entre duas vozes com opiniões divergentes acerca da homossexualidade. Por um lado, a voz heterossexual, que condena e que não coincide propriamente com a voz do narrador, mas que se filia nas categorias científico-moralizantes da sociedade da época; por outro, a voz homossexual, a do protagonista e até, se quisermos, um pouco a do narrador. 
Esta duplicidade de vozes, as ambiguidades e as ambivalências que vejo neste romance, no que diz respeito, sobretudo, à sexualidade, encontram sustentação de várias formas. Em primeiro lugar, parece-nos que o discurso amoroso neste livro transita de forma bastante significativa entre a fúria erótica, apresentada por metáforas animalescas, e uma representação que tem no seu centro a naturalidade de uma relação amorosa assente, neste caso, na genuína devoção que Amaro dedica a Aleixo, devoção que culmina num final trágico à boa maneira das tragédias românticas. Nesse sentido, poder-se-ia até dizer que esta narrativa condena os preconceitos de uma época e de uma sociedade marcadas pela hipocrisia e pelo moralismo. Aliás, não parece ser por acaso que Caminha (que se tinha demorado a descrever as cenas de sexo) se abstém de mostrar ao leitor Amaro, o negro, a passar a navalha no pescoço de Aleixo, e também não parece ser por acaso que o romance termina com a imagem da falta de solidariedade da multidão que se acumula na rua para ver, com um fascínio quase animalesco, o cadáver de Aleixo. Multidão que tão depressa se junta, como depressa se dispersa, reentrando na sua monotonia cotidiana. Interessante é, também, ver neste final um diálogo com o final de Iracema. A expressão "Tudo passa sobre a terra", que encerra o livro de Alencar, não é apenas uma fórmula romântica que aponta para a vida como passagem e a morte como vida verdadeira; é também uma forma de mostrar o silenciar da "raça" indígena (no final, a jandaia deixa de repetir o nome de Iracema). No caso de BomCrioulo, a imagem da multidão dispersando e caindo na "monotonia habitual, no eterno vaivém" não é, creio, apenas uma fórmula do naturalismo que aponta para uma visão determinista da vida; é também a indicação de que quando uma sociedade não é solidária e não se preocupa verdadeiramente com o "outro", acaba perpetuando preconceitos e comportamentos nocivos. Leia-se o trecho final do romance:

A rua enchia-se de gente pelas janelas, pelas portas, pelas calçadas. Era uma curiosidade tumultuosa e flagrante a saltar dos olhos, um desejo irresistível de ver, uma irresistível atração, uma ânsia! Ninguém se importava com o outro, com o negro, que lá ia, rua abaixo, triste e desolado, entre as baionetas, à luz quente da manhã: todos, porém, queriam ver o cadáver, analisar o ferimento, meter o nariz na chaga... Mas, um carro rodou, todo lúgubre, todo fechado, e a onda dos curiosos foi se espalhando, se espalhando, té cair tudo na monotonia habitual, no eterno vaivém (CAMINHA, 1991, p. 110).

A forma como, por vezes, o narrador desconstrói o seu aparente tom moralizador pode ser visto como outro exemplo de ambiguidade e ambivalência. Dito de outro modo, ao descrever os pensamentos de Amaro quando este pensa na sua atração sexual por elementos do mesmo sexo e, em particular, por Aleixo, o narrador utiliza, de fato, termos claramente 
negativos, como "anomalia", "comércio grosseiro" ou "castigo". Porém, logo a seguir, parece contrariar tanto essa posição moralizadora, quanto a associação entre raça e comportamentos sexuais desviantes. Tal é feito através da relativização da preferência sexual de Amaro, mostrando que esta preferência não era de todo uma exceção, nem era uma preferência exclusiva ao homem negro. Leia-se uma passagem e note-se que a desconstrução a que me refiro advém discursivamente tanto do uso da ironia inscrita na frase exclamativa, quanto do reconhecimento de que a natureza tem o poder de se sobrepor à vontade humana:

Não havia jeito, senão ter paciência, uma vez que a 'natureza' impunha-lhe esse castigo.

Afinal de contas era homem, tinha suas necessidades, como qualquer outro: fizera muito em conservar-se virgem até aos trinta anos, passando vergonhas que ninguém acreditava, sendo muitas vezes obrigado a cometer excessos que os médicos proíbem. De qualquer modo estava justificado perante sua consciência, tanto mais quanto havia exemplos ali mesmo a bordo, para não falar em certo oficial de quem se diziam cousas medonhas no tocante à vida particular. Se os brancos faziam, quanto mais os negros! É que nem todos têm força para resistir: a natureza pode mais que a vontade humana... (CAMINHA, 1991, p. 50).

A simplicidade e a dramaticidade que sobressaem desta passagem apela à solidariedade e à empatia do leitor. Na verdade, é o próprio Amaro que racionaliza sobre a sua sexualidade e mostra que ela é do domínio da contingência, sendo uma exigência natural, igual a de qualquer outro homem. Além disso, o fato de Amaro explicar que se conservou virgem até aos trinta anos confere-lhe não só um certo distanciamento das suas imposições sexuais, mas também uma certa aura de pureza, o que favorece o seu estatuto como o herói da narrativa, sendo exemplo de disciplina, dedicação e caráter. David Foster (1991) e Peter Frye (1982) argumentam a favor da ideia de Bom-Crioulo exibir características típicas de um herói, como a honestidade, honorabilidade, para além daquelas já mencionadas. Repare-se que o uso da técnica do discurso indireto livre permite a manipulação do ponto de vista enunciativo e, por conseguinte, facilita a comunicação com o leitor e pede-lhe para que este se coloque ao lado da personagem, desconstruindo com ela o discurso médico-social que condena a sua sexualidade.

Em $O$ retrato do imperador: negociação, sexualidade e romance naturalista no Brasil (2000), Leonardo Mendes afirma que a passagem acima citada é surpreendente, primeiro, porque "o personagem se utiliza da condenação do discurso médico à masturbação para justificar a si mesmo e aos leitores sua necessidade de ter uma vida sexual ativa e regular" (MENDES, 2000, p. 199); e, segundo, porque nela se articula "uma reivindicação à igualdade racial pela sexualidade" e, consequentemente, se abolem "todas as hierarquias e 
diferenças" e se unem "brancos e negros, oficiais e grumetes, numa humanidade comum de seres dotados de uma sexualidade que está inscrita na ordem natural” (MENDES, 2000, p. 200).

Outro aspecto que vai ao encontro das ambiguidades e ambivalências que acredito estarem presentes nesta narrativa encontra-se não só na normalidade com que se descreve o ato de Amaro e Aleixo andarem de braços dados na rua, assim como na normalidade com que dona Carolina aceita que os dois se instalem na sua casa. Tudo isto mostra que, apesar de num certo momento o narrador de Bom-Crioulo classificar a relação física entre Amado e Aleixo de um "delito contra a natureza" (CAMINHA, 1991, p. 47), os aspectos mais marcantes do romance são, como afirma Robert Howes (2005), a clareza das descrições e a atitude descompromissada do autor sobre o tema principal - a homossexualidade. As ambiguidades e ambivalências de Bom-Crioulo têm inspirado, com efeito, muitas interpretações que, segundo o levantamento de Howes, oscilam entre as propostas de ver no romance uma crítica dura ao castigo pela chibata na Marinha (castigo que acontecia por razões de indisciplina, ou como forma de punir comportamentos homossexuais), um regresso aos temas clássicos de Otelo e da relação entre o cavaleiro e seu escudeiro, uma crítica aguda da transição política entre Império e República, uma reflexão sobre os efeitos perniciosos da vida escrava na sociedade brasileira, um exemplo de lusofobia através do retrato negativo das personagens portuguesas, uma visão negativa do Brasil "preso entre a degeneração da sua população não-branca e os encantos murchos e estéreis da Europa e de seus imigrantes" (HOWES, 2005, p. 171) ou, ainda, uma reflexão em torno das questões de gênero e raça combinadas com a questão da sexualidade masculina e feminina.

Este conjunto de possíveis interpretações mostra, de resto, que a leitura de Flora Sussekind faz deste livro é demasiado limitadora, na medida em que retira do texto de Caminha todo um universo transformador que transpira na obra Bom-Crioulo. É certo que o romance não apresenta soluções definitivas, mas ao expor os problemas e as ambivalências centrais daquele momento histórico, força o leitor a pensar criticamente e a perceber o esforço que Caminha faz para problematizar o discurso científico e racialista da época (o discurso oficial da sociedade) e para pôr à vista do leitor uma realidade histórico-social complexa, em transformação e repleta de contradições. Se quisermos novamente aproximar Caminha de Alencar, poder-se-á até dizer que, pesem embora as diferenças, as ambivalências e as ambiguidade dos livros dos dois autores advêm, em grande parte, da enorme dificuldade de ambos articularem as suas ideias às estéticas literárias disponíveis no seu tempo. No que diz respeito à obra de Caminha, a fortuna crítica destaca justamente a ideia de que este autor 
não foi capaz de sair do esquema imposto pelos imperativos naturalistas. Leonardo Mendes é, a este propósito, muito esclarecedor ao ressaltar as tensões internas do autor/narrador, cuja preocupação em seguir as pesquisas médicas e científicas, à boa maneira dos naturalistas, ocultará muitas vezes os seus preconceitos ou as suas simpatias pelas personagens e suas emoções.

A argumentação de Mendes é bastante relevante, já que propõe que se analise o romance de Caminha a partir do conceito do gótico (cuja origem remonta às narrativas românticas de terror), uma vez que este conceito surge constantemente associado a condições existenciais ambíguas e conflituosas e, consequentemente, à homossexualidade - o crítico fundamenta a sua posição através de um vasto conjunto de manifestações literárias e de obras críticas que se têm debruçado sobre as relações entre o gótico e a homossexualidade. À luz da mundividência gótica, todos os objetos e espaços físicos estão associados à representação de decadência, ruínas e mistério. Em Bom-Crioulo, as descrições da velha corveta e da atmosfera triste e nostálgica da paisagem onde ela surge inserida, bem como a descrição do Sobradinho obscuro da Rua da Misericórdia e do seu quarto decadente são dois dos exemplos mais evidentes.

No geral, a análise deste crítico gira em torno dos valores relacionados com a figura do Imperador, cujo retrato se encontra na parede do quarto de Amaro e Aleixo. O apreço que Amaro nutre por este retrato remete tanto para o "poder moderador" exercido por D. Pedro II no meio político-social, como para o afeto das camadas mais pobres da sociedade brasileira pela figura do Imperador. Ler esta narrativa a partir do valor simbólico invocado pelo retrato possibilita olhar para uma sociedade em que os antagonismos, de uma forma ou de outra, acabam por coexistir ou por ser moderados. Uma ilustração dessa coexistência é, por exemplo, a relação pacífica entre os valores monárquicos do protagonista e os valores republicanos do autor, bem como a simultânea condenação e aceitação das "sexualidades periféricas" nesta história (para além da homossexualidade de Amaro, discute-se também a identidade sexual feminina através da figura de D. Carolina, uma mulher com traços de homem que seduz Aleixo, descrito como um hermafrodita e marcado por uma sexualidade plural).

Mendes alertou para o fato de a cosmovisão gótica ser, em essência, anticientífica, o que permitiu ao escritor abordar o tema da sexualidade mantendo a atmosfera de medo e mistério, desobrigado de tudo explicar - o gótico é frequentemente associado à ideia de mistério e de algo improferível. Vendo a narrativa sob este prisma, percebe-se uma vez mais que Caminha não estava interessado em classificar a homossexualidade como imoralidade, 
mas, sim, em colocar o assunto na mesa, forçando os leitores da sua época a debatê-lo com naturalidade. Penso, aliás, que é nesse esforço que se encontra o potencial transformativo deste livro. A morte de Aleixo no final do romance deve-se, por um lado, ao resultado direto da destruição psicológica que este opera na vida de Bom-Crioulo (que o ama a ponto de não aceitar a traição) e, por outro, aos impasses sociais em torno da homossexualidade, que fazem com que a morte de Aleixo seja a única solução para o desfecho desta narrativa do século XIX. Como observou Mendes,

[d]esse ponto de vista, não há dúvidas quanto ao alinhamento do romance: é Bom-Crioulo que [Caminha] escolhe perdoar, e é Aleixo que ele decide punir com a morte. A raiva do protagonista é a expressão mais eloquente de seu compromisso com um projeto de felicidade conjugal ao lado do grumete, de sua seriedade e fidelidade - traços de carácter que nenhum outro personagem no romance foi capaz de exibir. A fúria de Bom-Crioulo é, como sugere Adam Philips em um ensaio sobre a raiva, uma resposta à sabotagem e à traição; paradoxalmente, ela é também um gesto de recusa, insistência e esperança. A vingança organiza os farrapos de sua existência, mostra o que ele quer e o que a vida significa para ele. Com o assassinato de Aleixo (e mesmo que, no processo, ele destrua a própria vida), BomCrioulo mostra como o mundo e o amor devem ser (MENDES, 2000, p. 212).

No contexto da criação de uma literatura nacional brasileira, este romance adquire uma singularidade particular. Primeiro, não deixa de conter o elogio à paisagem natural do Brasil. Algumas descrições chegam mesmo a atingir um alto grau de lirismo. Vejamos dois excertos em que o narrador descreve a luz do sol tropical: "O céu tinha uma cor azul esverdeada, limpo de nuvens, alto e imenso na eterna glória da luz... Avezinhas de colo branco acompanhavam a corveta, pousando n'água, trêfegas e alvissareiras, misturando sua alegria ruidosa com o surdo marulhar das vagas, num rápido espanejamento d'asas" (CAMINHA, 1991, p. 39), e "em cima, no alto do grande hemisfério que a luz do meio dia incendiava, o azul sempre o azul claro, o azul imaculado, o azul transparente e doce, infinito e misterioso..." (CAMINHA, 1991, p. 42). Segundo, o romance coloca a figura do negro em primeiro plano narrativo, problematizando não só a situação da violência física e da escravatura nas dinâmicas de uma sociedade que recentemente a tinha abolido. Terceiro, expõe o funcionamento de uma instituição pública - a Marinha - que perpetuava comportamentos elitistas e racistas. E por último, ao eleger um tema tão controverso como a homossexualidade, Caminha mostra que as narrativas que trabalham temas relacionados com a construção da nação envolvem muitas vezes aquilo que Homi K. Bhabha (1990, p. 5) descreveu como "momentos de negação, deslocamento, exclusão e contestação cultural". 


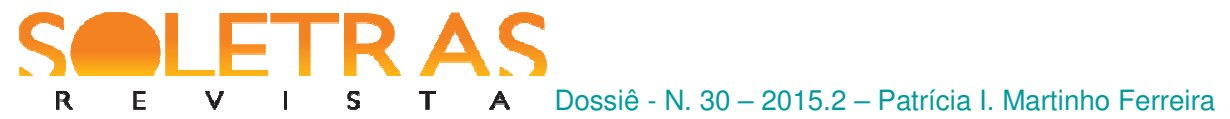

\section{Referências bibliográficas:}

ALENCAR, José de. Iracema. Lisboa: Livraria Bertrand, 1948.

BHABHA, Homi K. Nation and Narration. New York: Routledge and Keegan Paul, 1990.

CAMINHA, Adolfo. Bom-Crioulo. Rio de Janeiro: Prefeitura da Cidade do Rio de Janeiro, 1991.

CANDIDO, Antonio. Formação da literatura brasileira (1750-1836). V. 1, 9. ed. Belo Horizonte: Editora Itatiaia Limitada, 1975.

FOSTER, David William. Adolfo Caminha's Bom-Crioulo: a Founding Text of Brazilian Gay Literature. In: _. Gay and Lesbian Themes in Latin American Fiction. Austin: University of Texas Press, 1991, p. 9-22.

FRYE, Peter. Leonie, Pombinha, Amaro e Aleixo: prostituição, homossexualidade e raça em dois romances naturalistas. In: EULÁLIO, Alexandre (Org.). Caminhos cruzados. Linguagem, antropologia e ciências naturais. São Paulo: Brasiliense, 1982, p. 33-51.

HOWES, Robert. Raça e sexualidade transgressiva em Bom-Crioulo de Adolfo Caminha. Graphos. Revista de Pós-Graduação em Letras. João Pessoa: UFP, vol. 7, n. 2/1, p. 171-190, 2005.

HUTCHEON, Linda. Uma teoria da paródia: ensinamentos das formas de arte do século XX. Lisboa: Edições 70, 1989.

MENDES, Leonardo. O retrato do imperador: negociação, sexualidade e romance naturalista no Brasil. Porto Alegre: EDIPUCRS, 2000.

RENAN, Ernest. What is a nation? In: BHABHA, Homi K. Nation and Narration. New York: Routledge and Keegan Paul, 1990, p. 8-22.

SANTIAGO, Silviano. Alegoria e palavra em Iracema. Luso-Brazilian Review. Madison: University of Wisconsin, vol. 2, n. 2, p. 55-68, Winter, 1965.

SUSSEKIND, Flora. Tal Brasil, qual Romance? Rio de Janeiro: Achiamé, 1984.

VALENTE, Luiz Fernando. Alencar's Flawed Blueprints. In: EAKIN, Marshall C. Homenagem a Alexandrino Severino: Essays on the Portuguese-Speaking World. Austin: Host, 1993, p. 148-166.

Palmilhando a tradição alencariana: Um modelo intertextual de história literária. Revista de Crítica Literaria Latinoamericana, Año 20, n. 40, p. 141-154, 1994. 


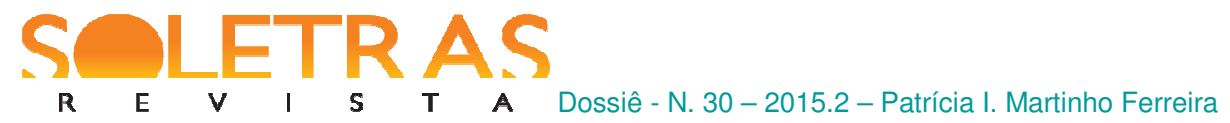

\title{
Nation, narration and naturalism in Adolfo Caminha's Bom-Crioulo
}

\begin{abstract}
Having in mind the idea of a literary system as formulated by Antonio Candido, the purpose of this paper is to establish a dialogue between Iracema (1865) by José de Alencar and Bom-Crioulo (1895) by Adolfo Caminha, with a twofold goal. First, it is to understand how Bom-Crioulo incorporates and expands the flaws and weaknesses of the political and social system established by the elites of the Empire, which are already inscribed between the lines of Alencar's novel. Second, it is to understand how Bom-Crioulo can contribute to the construction of Brazilian identity and therefore participate in the discourse regarding ideas of nation and narration. The main focus of this essay is Caminha's novel, although the starting point is given by the intertextual connection between this novel and Iracema.
\end{abstract}

Keywords: Nation. Narration. Brazilian identity. Bom-Crioulo. Intertextuality.

Recebido em: 26 de novembro de 2014.

Aprovado em: 22 de dezembro de 2015. 